\title{
A narrative review on the management of Acute Heart Failure in Emergency Medicine Department
}

\author{
Amin Saberinia (1,2), Ali Vafaei $(1,2)$, Parvin Kashani $(1,2)$ \\ (1) Department of Emergency Medicine, School of Medicine, Shahid Beheshti University of \\ Medical Sciences, Tehran, Iran; (2) Department of Emergency Medicine, School of Medicine, \\ Shahid Beheshti University of Medical Sciences, Loghman Hakim Hospital, Tehran, Iran \\ This article is distributed under the terms of the Creative Commons Attribution Noncommercial License (CC BY-NC 4.0) which permits \\ any noncommercial use, distribution, and reproduction in any medium, provided the original author(s) and source are credited.
}

\begin{abstract}
The main urgent symptom presented to an emergency department is acute heart failure (AHF). In that considerable risksof morbidity and mortality, it is important to plan precision medicine to achieve the most suitable outcomes. The object of this review is to provide a summary of contemporary management procedures of emergency medicine in a department of acute heart failure. Heart failure could be presented with a broad range of symptoms, in particular a sudden worsening of those of Chronic Obstructive Pulmonary Disease. The treatment should focus on acute and chronic underlying disorders with instructions focusing on haemodynamics and blood pressure status. Treatment of patients suffering with worsening symptoms of AHF mainly focuses on intravenous diuretics. In emergency situations, patients suffering with AHF with low blood pressure must receive emergency consultation and a primary fluid bolus therapy (range 250-500 mL) followed by inotropic therapy with or without antihypotensive agents. For treatment of severe heart failure and cardiogenic shock in patients treated with noradrenalin, when blood pressure support is required, a direct-acting inotropic agent, dobutamine, could be applied effectively. When non-invasive positive pressure ventilation is needed, suppliers must track for any possibility of sudden worsening, i.e., for acute decompensated heart failure. When cardiac output is high the disorder could be treated with vasopressors.
\end{abstract}

Key Words: Emergency medicine, heart failure, diagnosis, management.

Eur J Transl Myol 30 (1): xx1-xx8, 2020

The process of diagnosis and management within the emergency medicine department ought to be done carefully for a wide range of patients suffering with acute heart failure (AHF). Unluckily, the documents for management of emergency medicine departments are not boundless. ${ }^{1}$ This problem combined with heterogeneity of AHF patients cause great variability of the clinical therapy. The prospective influence of a management in emergency medicine department is also considerable, a delay in diagnoses process or application of suboptimal drug treatments would have considerable negative consequences. $^{2}$ The most sensitive decisions in management of emergency medicine are decision of patient hospitalization and selection of the most effective healthcare procedures. The main subject of this study is to describe epidemiology and pathophysiology of acute heart failure within an emergency medicine department. ${ }^{3}$ Figure 1 shows that HF is a consequence of an inadequate performance of the left ventricle caused by two or more chronic diseases. These disorders include valvular heart diseases, narrowing or blockage of coronary arteries, very high blood pressure, structural disorders of heart and blood vessels, and diabetes. Though many patients present symptoms of inappropriate left ventricle function, $\mathrm{HF}$ is not equivalent to dysfunction of left ventricle or cardiomyopathy. ${ }^{4}$ Low ejection fraction (EF) is important for prognosis of HF, but patients with preserved ejection fraction would still be diagnosed with symptomatic HF. ${ }^{5}$

\section{Methods}

The information for this study was collected from the two comprehensive databases of PubMed and Google Scholar by searching the keywords Emergency medicine, Heart failure, Diagnosis and management. The language of literature search was English. At the beginning of the search 98 records were identified. All relevant studies were overviewed and the records which were subjectspecific to the aim of this study were selected for careful and detailed study. Randomized scientific experiments, 


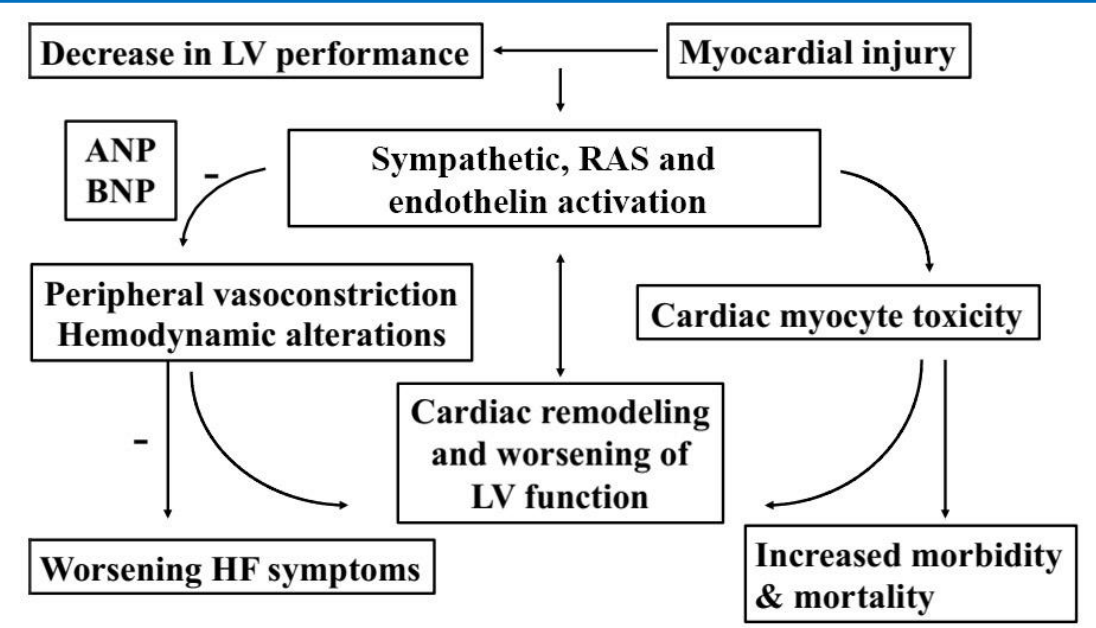

Fig 1. Pathophysiology of heart failure. Derived in accordance to Dick CK, Frank $P(2015)^{6}$ Left ventricle $(L V)$, renin-angiotensin system (RAS), atrial natriuretic peptide (ANP), B-type natriuretic peptide $(B N P)$, heart failure $(H F)$.

cohort studies of prospective and retrospective designs, epidemiological observational studies, systematic metaanalysis reviews and critical analysis of the literature were selected. At the end of this process, 49 articles were chosen for this study.

\section{$A H F$ and acute respiratory failure}

AHF disorder may cause failure of biological respiratory system up to sudden death. In such an occasions, due to the high risks for patients simultaneous diagnosis and management is mandatory. Heart arrhythmia, infection and acute coronary syndrome are main hidden causes of their occurrence. ${ }^{7}$ Those patients who do not respond to external stimuli and suffer with severe respiratory failure need endotracheal intubation and/or assisted ventilation. On the other hand, in patients suffering with acute respiratory distress syndrome but who are awake and cooperative, urgent noninvasive positive-pressure ventilation notably reduces death. ${ }^{8}$

\section{Early medical diagnosis and evaluation}

Organizing the diagnosis process is essential in emergency medicine, but unfortunately it is not such easy. Fatigue, dizziness, breath shortness, swelling, decreased ability to perform physical exercise, weakness, chest pain and increased body weigh could be common symptoms of AHF.

Aggravating heart failure, new onset of AHF, obvious cardiogenic shock and rapid onset of hypertension pulmonary edema are the most frequent form of AHF. In spite prevalence of AHF in emergency medicine department be high, its diagnosis may be missed or delayed in one third of patients. ${ }^{9}$ Thus, timely diagnosis of AHF is a very important factor to start in time treatments, that would decrease the risks of long hospitalization and/or inpatient mortality. ${ }^{10}$

Due to the lack of specific signs in physical examination, biological markers or clinical imaging AHF diagnosis have not appropriately improved. Shortness of breath is the most frequent symptom which forces AHF patients to take care of themselves and mostly will occur because of vascular congestion. Differentiating AFH from other causes of shortness of breath is very challenging, particularly for patients who are without any previous diagnosis of HF and also for those patients who suffer from other chronic episodic disorders of acute obstructive lung disease. ${ }^{11}$ Anyway, symptoms which are connected with HF, like paroxysmal nocturnal dyspnoea (PND) and shortness of breath are present in about 50\% of AHF patients. Congestion is often the underlying reason of patient symptoms and signs, but quantifying congestion is still challenging. Positive effects of natriuretic peptides are the most beneficial to improve AHF diagnosis. ${ }^{12,13}$

In patients presenting to the emergency medicine department with shortness of breath disorder, concentration of $300 \mathrm{pg} / \mathrm{mL}$ and $100 \mathrm{pg} / \mathrm{mL}$ as $\mathrm{N}$ terminal (NT)-proBNP and B-type natriuretic peptide (BNP) cutoff points, respectively, could significantly decrease AHF by pre- and post- probability test. ${ }^{11}$ The higher amounts of BNP could be helpful in management of proper diagnois in AHF patients, while intermediary values of BNP (ranging from 100 to $800 \mathrm{pg} / \mathrm{mL}$ ) does not have the specificity to confirm diagnosis. Ratios of probability corresponding to the highest values of NTproBNP could benefit the process of AHF diagnosis modestly. ${ }^{11}$ The special proficiency of these biological markers overhead of the specified aforementioned cutoff points are restricted via kidney failure and age advancement. $^{12}$ Additionally, some other limiting situations in patients with higher values of BNP are syndrome of acute respiratory failure, complex disorder of pulmonary hypertension, blockage within the pulmonary arteries and cardiovascular disease of valvular heart. ${ }^{14-16}$ 
Table 1. The major objectives of management of emergency medicine department. Derived in accordance with Benton RH et al. ${ }^{25}$

I Assurance of safety and dependability of the breathing, upper airway and immediate resuscitation and circulation

II Recognition and treatment of any other possible threats of life

III Certified diagnosis of AHF disorder and reliable treatment

IV Recognition of the AHF precipitant and modification of treatment

$\mathrm{V}$ Detection of patients in various situations by considering the potential contribution whether they need immediate treatment

VI Patient reevaluation to ensure improvement in clinical symptoms and in dynamics of blood flow

VII Patients Stratification into various health risk tiers

VIII Planning of discharge disposition process, including the steps of admission, observation, and discharge

Furthermore, complete blood count and blood test of basic metabolic panel and also the test of troponin $\mathrm{T}$ or troponin I proteins blood levels must be considered amongst patients with AHF. Intermittently, the test of troponin proteins levels would discover potential acute coronary syndrome as a significant AHF precipitant. ${ }^{17}$ Anyhow, higher levels of troponin protein could not have any role in acute coronary syndrome, because a lot of patients with AHF would release various levels of troponin protein. ${ }^{18}$

Due to the broad restriction of the process of laboratory isolation testing, novel imaging techniques play a considerable role in AHF diagnosis. In this regard, chest $\mathrm{X}$-ray radiography is known to be one of the main components of the diagnostic examination process. X-ray radiography could easily recognize alveolar edema, interstitial edema, and redistribution of hilum of the lung and also various reasons of shortness of breath. ${ }^{19}$ Ultrasonography of the lungs is an important functional tool for patient care, recognizing edemas of the lungs and AHF. ${ }^{20}$ One the best tools for diagnostic examination of HF patients is echocardiogram (echo) test. Though transthoracic echocardiography does not commonly exist in emergency medicine department, focused heart ultrasound within the emergency medicine department could be applied as an effective point-of-care testing tool for assessing left ventricular dysfunction. ${ }^{21}$

Visual assessment of decreased normal left ventricular ejection fraction could be done through evaluating ventricular septum inward movement and left ventricle inferior wall pending systole and also through observing the excursion degree of the anterior leaflet of the bicuspid valve in the direction of the ventricular septum when the heart refills with blood after the emptying during systole. These evaluations are associated with quantitative EF echocardiographic measurements. ${ }^{22}$ Reduction in Ejection fraction (EF) is easily diagnosed by a physician in emergency medicine department. Indeed, focused cardiac ultrasound could differentiate AHF disorder from alternative reasons of shortness of breath with sensitivities ranging from 75 to $85 \% .{ }^{23}$

\section{Early managements}

When diagnosis is performed, phenotypic presentation and main causes of disease aggravation guide the procedure of early treatment. Anyhow, knowledge about hemodynamic and respiratory stability is one of the most important factors. Table 1 shows the objectives of managements in emergency medicine department. Meanwhile addressing the respiratory status of patient, the AHF precipitant must be investigated, diagnosed and treated. Irregular and often rapid heart rate, acute coronary syndrome, embolism of the lungs, underlying chronic infection could all causes of AHF disorder. ${ }^{24}$

\section{Preliminary classification}

According to Pang et al. ${ }^{26}$ the process of grouping patients who may suffer from AHF should be done via systolic blood pressure (SBP). On the other hand, the level of acute coronary syndrome at the presentation time is high $(>140 \mathrm{mmHg}) .{ }^{26}$ The status of ventricular volume overload would not be seen amongst all patients; as an instance, patient with pulmonary edema could be mentioned. ${ }^{27}$ The main clinical presentation of these patients would be apparent volume of distribution or vascular failure. Additionally, most of the time, in these patients amongst the clinical symptoms could be present elevated systolic blood pressure. ${ }^{28}$

\section{First-Line Treatment}

Currently, there is not any novel Level I treatment for AHF. The treatments are mostly alike those utilized forty years ago (Table 2). Anyhow, congesting cuffs and phlebotomy are not applied any more, demonstrating a significant progression in the medical debatable. On the other hand, the absence of robust, randomized documented medical research is the main cause of hemodynamic improvement, ineffectiveness in achieving symptom relief and in achieving the appropriate decongestion strategy. ${ }^{29}$

\section{AHF disorder patients with hypotension}

Worsening of heart failure could rarely cause a shock proportional to other types of AHF. Due to infrequent 
Acute Heart Failure

Eur J Transl Myol 30 (1): xx1-xx8, 2020

Table 2. Documented perspective of remedial alternatives for AHF early treatment. Derived in accordance with with Benton RH et al. ${ }^{25}$

\begin{tabular}{|c|c|}
\hline 1970 s & 2019 \\
\hline Patient sits elevated with head and upper body raised & Patient sits elevated with head and upper body raised \\
\hline Applying oxygen therapy & Applying oxygen therapy \\
\hline $\begin{array}{c}\text { Applying airway pressure to the patient's airway } \\
\text { through an endotracheal or tracheostomy tube }\end{array}$ & $\begin{array}{c}\text { Applying airway pressure to the patients airway } \\
\text { through an endotracheal or tracheostomy tube }\end{array}$ \\
\hline Pain reduction with Morphine & Pain reduction with Morphine \\
\hline Water pills (Diuretics) & Water pills (Diuretics) \\
\hline Intra-aortic balloon (IAB) & Intra-aortic balloon (IAB) \\
\hline Phlebotomy technique & Inotropic agents \\
\hline Congesting cuffs & Natrecor/Vasodilators drugs \\
\hline
\end{tabular}

presentation of AHF with complexness of pathophysiology, precipitant, structure of the heart, functional responsibility and also the status of hemodynamic monitoring, management process could be challenging. ${ }^{30}$ Additionally, patients who suffer from progressive heart failure would present with low systolic blood pressure. On the other hand, in patients with reduced severely EF, an ordinary systolic blood pressure would not be attainable and abnormally rapid heart rate would be the main contributor to cardiac output. Fluid bolus administration would be a therapeutic reflexive action for patients with low systolic blood pressure. ${ }^{31}$

But in the hypoperfusion setting due to cardiac failure, administration of fluid bolus would increase edema of the lungs. Increment of urine production and infection are frequent precipitants which would properly respond to the fluid. Anyhow, in emergency patients who suffer with progressive HF disorder evaluating the volume status is challenging. ${ }^{32}$

As previously mentioned, the sonography technique would be beneficial, but it should be noted that the reaction to First-Line treatments is recognized to be the most effective guidance for further managements. On the other hand, patients with AHF disorder who suffer from cumulative low systolic blood pressure too would need complex decongestive therapy. However, these situations infrequently would be put in application in emergency medicine department because they could accelerate circulatory failure ${ }^{33}$

\section{Vasopressors and inotropic medications}

Table 3 lists applicable antihypotensive and inotropic agents. In spite of the fact that vasodilators and inotropes could modify the dynamics of blood flow, none of them are able to provide more preferable clinical outcomes. As a matter of fact, and by referencing previous studies, existing inotropic agents could cause damages. ${ }^{34}$ With regard to antihypotensive agent (vasopressors), there are not adequate robust data for advocating one agent over another. De Backer et $\mathrm{al}^{35}$ by conducting large randomized experiments found that, a mortality increment among patients with sudden cardiogenic shock would occur in consequence of using dopamine in comparison with norepinephrine. ${ }^{35}$

\section{Patients with hypertension disorder}

Almost fifty percent of patients who have AHF, represent hypertension at the range of acute coronary syndrome $\geq$ $140 \mathrm{mmHg}$. Edema of the lungs in older patients who preserved Ejection fraction and have further acute beginning of symptoms, could be happened through vascular redistribution. Intrinsically, in such situations vasodilation agents are the main components of the treatment process. ${ }^{30}$ Yancy et al ${ }^{[36]}$ recommended that, amongst the effective agents of vasodilation, trinitroglycerin (TNG) place at the first line of therapy. ${ }^{36}$ In accordance with clinical specialists at the emergency medicine department which are familiar with TNG, this inexpensive agent could be applied quickly through invasive technique of intravenous and sublingual routes. Discrete amount of doses at the range of $2-3 \mathrm{mg}$ are proficiently effective and tolerated, but a lot of clinicians are not willing to prescribe large doses like this. ${ }^{37}$

In an anecdotal manner, TNG as an intravenous drip therapy is frequently withheld because of its need for an intensive therapy unit bed. Anyway, the capability of quick onset/offset of TNG make it an arbitrary titratable medication to initiate rather than changing to alternative remedies. Nesiritide and sodium nitroprusside are alternatives to TNG. Same as TNG, neither nesiritide nor sodium nitroprusside has been demonstrated to enhance morbidity or mortality in AHF. ${ }^{38}$ Anyway, both of them are beneficial vasodilation agents, alongside sodium nitroprusside which is the more powerful one. While the main function of TNG is to improve the heart venous circulation evet at higher doses, sodium nitroprusside acts quickly on both the venous and arterial circulation. In such situations, the blood pressure would drop quickly, so the process should be kept under observation accurately. One the most well investigated vasodilation agents with regard to large-scale randomized clinical trials, is nesiritide. ${ }^{39}$

In spite of the fact that there are not many documents which specified acute ACEI application in emergency 
Acute Heart Failure

Eur J Transl Myol 30 (1): xx1-xx8, 2020

Table 3. Frequently used vasopressors and inotropes. Derived in accordance with with Benton RH et al. ${ }^{25}$

\begin{tabular}{|c|c|c|c|}
\hline Agents & $\begin{array}{c}\text { Levels of Evidence } \\
\text { (The Class of Recommendation) }\end{array}$ & Primary doses & Range of infusion \\
\hline Dobutamine & Level B (IIB) & $2-3 \mathrm{ucg} / \mathrm{kg} / \mathrm{min}$ & $2-20 \mathrm{ucg} / \mathrm{kg} / \mathrm{min}$ \\
\hline $\begin{array}{c}\text { Primacor } \\
\text { Milrinone) }\end{array}$ & Level B (IIB) & - & $0.375-0.75 \mathrm{ucg} / \mathrm{kg} / \mathrm{min}$ \\
\hline Levosimendan & Not specified & - & $0.05-0.2 \mathrm{ug} / \mathrm{kg} / \mathrm{min}$ \\
\hline Dopamine & Level B (IIB) & $2-5 \mathrm{ucg} / \mathrm{kg} / \mathrm{min}$ & $2-50 \mathrm{ucg} / \mathrm{kg} / \mathrm{min}$ \\
\hline Noradrenalin & Not specified & - & $0.2-1.0 \mathrm{ucg} / \mathrm{kg} / \mathrm{min}$ \\
\hline Trinitroglycerin & Level A (IIB) & $\begin{array}{c}5-20 \mathrm{ucg} / \mathrm{min} \\
\text { (Rapid titration) }\end{array}$ & $\begin{array}{c}5-200 \mathrm{ucg} / \mathrm{min}(\mathrm{Rapid} \\
\text { titration) }\end{array}$ \\
\hline $\begin{array}{c}\text { Sodium } \\
\text { nitroprusside }\end{array}$ & Level A (IIB) & $5-10 \mathrm{mcg} / \mathrm{min}$ & $\begin{array}{c}0.25 \mathrm{ucg} / \mathrm{kg} / \mathrm{min}- \\
10 \mathrm{ucg} / \mathrm{kg} / \mathrm{min}\end{array}$ \\
\hline Natrecor & Level A (IIB) & - & $0.01 \mathrm{ucg} / \mathrm{kg} / \mathrm{min}$ \\
\hline $\begin{array}{c}\text { ACE inhibitor } \\
\text { enalaprilat }\end{array}$ & Not specified & $\begin{array}{c}1.25-5 \mathrm{mg} \mathrm{IV} \\
\text { bolus q6 hrs }\end{array}$ & $\mathrm{NA}$ \\
\hline
\end{tabular}

medicine department, these pharmaceutical drugs could be adequately applied within the AHF. ${ }^{40}$ One of the most common mistaken beliefs is that the ACEI benefit in chronic heart failure with decreased Ejection fraction (EF) increase to the acute setting. On the other hand, in accordance with history, the application of morphine within AHF is still carried on. But it should be noted that, the extra usage of morphine for AHF could enhance the death risk among patients who are treated with. Consequently, due to the lack availability of documented studies about the dangerous doses of morphine, this study recommends against application of routine morphine in AHF patients. ${ }^{41}$

\section{Patients with normal blood pressure}

The normal blood pressure is within the range of acute coronary syndrome $100-140 \mathrm{mmHg}$ and it should be noted that AHF patients who placed in this range infrequently would present in the emergency medicine department in extremis. ${ }^{60}$ However, the patients who are in this situation would report a lazy for long periods of time and also will gain considerable weight. The process of relieving congestion via intravenous loop diuretic therapy is the primitive one for treatment process. In fact, there is not any differences between the application of continuous infusion of the loop diuretics or/and discrete amount of that. ${ }^{81}$ Within their study Felker et al (2011) reported that higher doses of intravenous therapy could increase the urine production and slightly improve the shortness of breath during the first three days and additionally could likely elevate the level of creatinine. ${ }^{81}$ As well as the application of diuretic therapy, vasodilation therapy in lower doses must be considered in patients who have normal blood pressure.

\section{Outcome and consequences}

In accordance with Storrow et al. ${ }^{42}$ most of patients who visit emergency medicine department will back home, based on doctor's recommendation and only about ten percent of them would be hospitalized. Anyway, approximately all of patients with AHF disorders (about $90 \%$ of them) who visit emergency medicine department are hospitalized. The analysis of collected organized data proposed that about half of AHF patients could be observed of discharged briefly and released. ${ }^{43}$ As a developing disorder, the symptoms of AHF could not be acceptably quickly diagnosed after hospitalization. Consequently, the emergency physicians know AHF as a high risk disorder. Due to the fact that, the main procedure of risk stratification in AHF patients concentrates on characterizing and defining patients in higher risks, the process of safe patient's diagnosis for sending them to home from the emergency medicine department is still challenging. ${ }^{44}$

In spite of the availability of some risk assessment instruments like Emergency Heart Failure Mortality Risk Grade (EHMRG), AHF Index, St. Thomas's Risk Assessment Tooling Falling Elderly Inpatients (STRATIFY) and Ottawa Heart Failure Risk Scale (OHFRS), none of these tools have been accepted broadly, because of their requirement for additional validation, diversity of patient populations and also restricted information on their outcomes for patients who discharged with lower risk AHF. ${ }^{45}$ However, one of the main challenging factors for further investigation in this regard is recognizing patients with lower risk of AHF for being discharged from the emergency medicine department. The lack of high risk features characteristics including low blood pressure, High concentrations of Btype natriuretic peptide, aggravated renal dysfunction, raised troponin complex and/or low sodium levels in the blood should not be confused with the absence of any risks. ${ }^{38,44}$

Afterwards, the absence of heart attack through highsensitivity cardiac troponin assay could identify patients with lower risks. ${ }^{46}$ With the help of improved 


\section{Acute Heart Failure}

Eur J Transl Myol 30 (1): xx1-xx8, 2020

stratification of risk, suitable choice of patients for proper medical care in the units of short-stay or observation among patient with AHF could become easier. The emergency medicine department units of observation or short-stay could provide additional time for the process of separating patient populations into high-low risk patients, the response of gauge to the patient's therapeutic method, produce more information about patients, create the most careful list of potential medications which patients could use and also simplify the process of patients follow up. ${ }^{47}$ As a fact, it should be noted that these assignments are not much easy during a short stay at the emergency medicine department. In addition, by considering the unwillingness to discharge patients with lower-risk AHF from the emergency medicine department, the application of observation medicine units for providing alternative medical spaces for short-stay emergency medicine department purposes as a medical bridge would be more attainable clinically and admissible to physicians of emergency medicine department. ${ }^{7}$

In patients with higher levels of risk, hospitalization would be proposed more beneficially for improving symptoms, optimization of intravascular volume status and also certify starting of instruction to manage chronic medical therapy. Specific pharmacological treatments of AHF are not specified with confidence to improve consequences of patients after being discharged. ${ }^{48}$ Anyway, the process of hospitalization would help the patients with higher risks for achieving symptomatic relief, optimizing the medical status and euvolemic decongestion. On the other hand, patients who suffer from de novo heart failure must be hospitalized, to recognize potentially or reversible causes. Additionally, these patients would need some medical knowledge about the ways in which new chronic illness could be managed by themselves. It should be noted that, the admission of patients indiscriminately could not be translated to reasonable cost or patient-centered benefit care. However, recognition of patients who could be properly observed or discharged from emergency medicine department is still a not fulfilled requirement. ${ }^{49}$

\section{Coclusions}

The process of AHF management in emergency medicine departments concentrates on diagnosis, stabilization, recognition of AHF precipitant, risk-stratification and early treatments. The outcomes of this study suggest that early therapy process should be according to phenotype presentation, using vasodilator agents and diuretics. Despite novel treatments exist and could improve symptoms, none of them certainly enhance the outcomes. Novel treatments that could save life of all AHF patients are not yet achieved. Anyway, in accordance with worldwide emergency medicine department policy all AHF patients should be admitted quickly. On the other hand, recognition of patients who are at low risk and may be discharged and followed up closely at home may produce enormous savings to the national health system.

\section{List of acronyms}

$\mathrm{AHF}$ - acute heart failure

ANP - atrial natriuretic peptide

BNP - B-type natriuretic peptide

$\mathrm{EF}$ - ejection fraction

$\mathrm{HF}$ - heart failure

$\mathrm{LV}$ - left ventricle

RAS - renin-angiotensin system

TNG - Trinitroglycerin

\section{Authors contributions}

All authors equally contributed to manuscript.

\section{Acknowledgments}

We thanks the School of Medicine, Shahid Beheshti University of Medical Sciences, Tehran, Iran

\section{Funding}

No funding was obtained for this research.

\section{Conflict of Interest}

The authors declare that they have no conflicts of interest.

\section{Ethical Publication Statement}

We confirm that we have read the Journal's position on issues involved in ethical publication and affirm that this report is consistent with those guidelines.

\section{Corresponding Author}

Parvin Kashani, Department of Emergency Medicine, School of Medicine, Shahid Beheshti University of Medical Sciences, Tehran, Iran

Tel: 02151025000

Email: P_kashani_md@yahoo.com

E-mails of co-authors

Amin Saberinia: amin.saberinia@gmail.com Ali Vafaei:

\section{References}

1. Kamilè C, Tuija J, Raphaël C, et al. Acute Heart Failure Management. Korean Circ J 2018:48: 46380.

2. Pang PS, Schuur JD. Emergency departments, acute heart failure, and admissions: one size does not fit all. JACC Heart failure 2014;2:278-80.

3. Gang L, Bryan LS, Flory LN, et al. Predicting Appropriate Hospital Admission of Emergency Department Patients with Bronchiolitis: Secondary Analysis. JMIR Med Inform 2019;7:e12591.

4. Schrager J, Wheatley M, Georgiopoulou V, et al. Favorable bed utilization and readmission rates for emergency department observation unit heart failure patients. Acad Emerg Med 2013;20:554-61.

5. Yancy $\mathrm{CW}$, Jessup $\mathrm{M}$, Bozkurt $\mathrm{B}$, et al. ACCF/AHA guideline for the management of heart 


\section{Acute Heart Failure}

Eur J Transl Myol 30 (1): xx1-xx8, 2020

failure: a report of the American College of Cardiology Foundation/American Heart Association Task Force on practice guidelines. Circulation 2013;128:e240-327.

6. Dick CK, Frank P. Diagnosing and managing acute heart failure in the emergency department. Clin Exp Emerg Med 2015;2:141-9.

7. Pang PS, Zaman M. Airway Management \& Assessment of Dyspnea in Emergency Department Patients with Acute Heart Failure. Current emergency and hospital medicine reports 2013;1:122-5.

8. Rochwerg B, Brochard L, Elliott MW, et al. Official ERS/ATS clinical practice guidelines: noninvasive ventilation for acute respiratory failure. Eur Respir J. 2017;50:1602426.

9. Salah K, Kok WE, Eurlings LW, et al. A novel discharge risk model for patients hospitalised for acute decompensated heart failure incorporating $\mathrm{N}$ terminal pro-B-type natriuretic peptide levels: A European coLlaboration on Acute decompeNsated Heart Failure: ELANHF Score. Heart (British Cardiac Society) 2014;100:115-25.

10. Wong YW, Fonarow GC, Mi X, et al. Early intravenous heart failure therapy and outcomes among older patients hospitalized for acute decompensated heart failure: findings from the Acute Decompensated Heart Failure Registry Emergency Module (ADHERE-EM). Am Heart J 2013;166:349-56.

11. Martindale JL. Resolution of sonographic B-lines as a measure of pulmonary decongestion in acute heart failure. Am J Emerg Med 2016;34:1129-32.

12. Zhipeng C, Yuqing J, Baoli Z. BNP and NTproBNP as Diagnostic Biomarkers for Cardiac Dysfunction in Both Clinical and Forensic Medicine. Int J Mol Sci 2019;20:1820; doi:10.3390/ijms20081820.

13. Christ M, Mueller C. Call to action: initiation of multidisciplinary care for acute heart failure begins in the emergency department. Eur Heart J Acute Cardiovasc Care. 2016;5:141-9

14. Nithianandan H, Reilly A, Wells P. Regarding the necessity of an updated meta-analysis on the prognostic value of serum biomarkers in patients with pulmonary embolism. Thromb Res 2019; 176:8-10. doi: 10.1016/j.thromres.2019.02.005.

15. Alberto P, Gaetano R, Behar C, et al. Combined BNP and Echocardiographic assessment in interstitial lung disease for pulmonary hypertension detection. Int J Cardiol. 2015 15;178:34-6

16. Frederique EP, Bas LK, Judith H, et al. Biological variation of cardiac markers in patients with aortic valve stenosis. Open Heart 2019;6:e001040.

17. Braga JR, Tu JV, Austin PC, et al. Outcomes and care of patients with acute heart failure syndromes and cardiac troponin elevation. Circulation Heart failure 2013;6:193-202.
18. James L. J, Gerasimos F, Markku N, et al. Troponin elevation in patients with heart failure: on behalf of the third Universal Definition of Myocardial Infarction Global Task Force: Heart Failure Section. European Heart Journal 2012;33;18:226571.

19. Ponikowski P, Voors AA, Anker SD, et al. 2016 ESC Guidelines for the diagnosis and treatment of acute and chronic heart failure: The Task Force for the diagnosis and treatment of acute and chronic heart failure of the European Society of Cardiology (ESC). Developed with the special contribution of the Heart Failure Association (HFA) of the ESC. Eur J Heart Fail 2016;18:891-975.

20. Frances MR, Peter SP. Acute Heart Failure Risk Stratification in the Emergency Department: Are We There Yet? Rev Esp Cardiol 2018;72:190-1.

21. Bakosis G, Christofilis I, Karavidas A. Treatment goals and discharge criteria for hospitalized patients with acute heart failure. Continuing Cardiology Education 2017;3:87-124 doi.org/10.1002/cce2.58.

22. Unluer EE, Karagoz A, Akoglu H, et al. Visual estimation of bedside echocardiographic ejection fraction by emergency physicians. West J Emerg Med 2014;15:221-6.

23. Susanna P, Elke P, Louise C, et al. Echocardiography and lung ultrasonography for the assessment and management of acute heart failure. Nature Reviews Cardiology 2017;14:427-40.

24. Dimitrios F, John P, John L, et al. Acute Heart Failure: Epidemiology, Risk Factors, and Prevention. Rev Esp Cardiol 2015;68:245-8.

25. Benton RH, Jennifer M, Osama A, et al. Approach to Acute Heart Failure in the Emergency Department. Cardiovascular Diseases 2017. doi: 10.1016/j.pcad.2017.08.008.

26. Pang PS, Collins SP, Miro O, et al. The role of the emergency department in the management of acute heart failure: An international perspective on education and research. Eur Heart $\mathbf{J}$ Acute Cardiovasc Care 2017;6:421-9. doi: 10.1177/2048872615600096. Epub 2015 Aug 11.

27. Pierpaolo P, Kuldeep K, Andrew LC. Fluid Management in Patients with Chronic Heart Failure. Card Fail Rev 2015;1:90-5.

28. Fallick C, Sobotka PA, Dunlap ME. Sympathetically mediated changes in capacitance: redistribution of the venous reservoir as a cause of decompensation. Circulation Heart failure 2011;:669-675.

29. Carson PE, Anand IS, Win S, et al. The Hospitalization Burden and Post-Hospitalization Mortality Risk in Heart Failure With Preserved Ejection Fraction: Results From the I-PRESERVE Trial (Irbesartan in Heart Failure and Preserved Ejection Fraction). JACC Heart Fail 2015;3:429-41.

30. Tsuyoshi S, Atsushi S, Shoji H, et al. Clinical characteristics of hospitalized heart failure patients 


\section{Acute Heart Failure}

Eur J Transl Myol 30 (1): xx1-xx8, 2020

with preserved, mid-range, and reduced ejection fractions in Japan. ESC Heart Fail 2019;6: 475-86.

31. Lam CS, Borlaug BA, Kane GC, et al. Ageassociated increases in pulmonary artery systolic pressure in the general population. Circulation 2009;119:2663-70.

32. Mebazaa A, Yilmaz MB, Levy $P$, et al. Recommendations on pre-hospital \& early hospital management of acute heart failure: a consensus paper from the Heart Failure Association of the European Society of Cardiology, the European Society of Emergency Medicine and the Society of Academic Emergency Medicine. Eur J Heart Fail 201;17:544-58.

33. Mebazaa A, Motiejunaite J, Gayat E, et al. Longterm safety of intravenous cardiovascular agents in acute heart failure: results from the European Society of Cardiology Heart Failure Long-Term Registry. Eur J Heart Fail 2018;20:332-41.

34. Afsar B, Ortiz A, Covic A, et al. Focus on renal congestion in heart failure. Clinical Kidney Journal 2016;9:39-47.

35. De Backer D, Biston $\mathrm{P}$, Devriendt $\mathrm{J}$, et al. Comparison of dopamine and norepinephrine in the treatment of shock. N Engl J Med 2010;362:779-89.

36. Yancy CW, Jessup $\mathrm{M}$, Bozkurt B, et al. ACCF/AHA Guideline for the Management of Heart Failure: Executive Summary: A Report of the American College of Cardiology Foundation/American Heart Association Task Force on Practice Guidelines. Circulation 2013;128:e240-327. doi: 10.1161/CIR.0b013e $31829 \mathrm{e} 8776$.

37. Fermín L, Hector R.C, Christian C.L, et al. Treatment of Hypertensive Cardiogenic Edema with Intravenous High-Dose Nitroglycerin in a Patient Presenting with Signs of Respiratory Failure: A Case Report and Review of the Literature. Am J Case Rep 2019;20:83-90.

38. Salvatore DS, Laura M. Drug Therapy for Acute Heart Failure. Rev Esp Cardiol 2015;68:706-13.

39. Emelia JB, Paul M, Alvaro A, et al. Heart Disease and Stroke Statistics - 2019 Update: A Report from the American Heart Association. Circulation 2019;139: e56-e528. DOI: 10.1161/CIR.00000000 00000659 .
40. Sam LT, Alan SM, Alan BS. Challenges in Acute Heart Failure Clinical Management: Optimizing Care Despite Incomplete Evidence and Imperfect Drugs. Crit Pathw Cardiol 2015;14:12-24.

41. Neal LW, Sean PC, Peter SP, et al. AHA Scientific Statement Acute Heart Failure Syndromes: Emergency Department Presentation, Treatment, and Disposition: CurrentApproaches and Future Aims. Circulation 2010;122:1975-96.

42. Storrow A, Jenkins C, Self WH, et al. The Burden of Acute Heart Failure on US Emergency Departments. Journal of The American College of Cardiology: JACC Heart Fail 2014;2:269-77. doi: 10.1016/j.jchf.2014.01.006. Epub 2014 Apr 30.

43. Sean PC, Peter SP.. ACUTE Heart Failure Risk Stratification. Circulation 2019;139:1157-1161.

44. Lee DS, Ezekowitz JA. Risk stratification in acute heart failure. Can J Cardiol2014;30:312-9.

45. Hsiao J, Motta M, Wyer P. Validating the acute heart failure index for patients presenting to the emergency department with decompensated heart failure. Emerg Med J 2012;29(12): e5.

46. Peter SP, Gregory JF, Benton RH, et al. TACIT (High Sensitivity Troponin T Rules Out Acute Cardiac Insufficiency Trial). Circ Heart Fail 2019;12: e005931. doi: 10.1161/CIRCHEART FAILURE.119.005931.

47. Shawna DB, Merri LB, Stephen LK, et al. Impact of an Emergency Department Observation Unit Management Algorithm for Atrial Fibrillation. J Am Heart Assoc 2016;5:e002984 doi: 10.1161/JAHA.115.002984.

48. Ibanez B, James S, Agewall S, et al. ESC Guidelines for the management of acute myocardial infarction in patients presenting with ST-segment elevation: The Task Force for the management of acute myocardial infarction in patients presenting with ST-segment elevation of the European Society of Cardiology (ESC). European Heart Journal, 2017;39:119-77.

49. Evandro TM, Antonio J, Luciana MR, et al. Understanding Hospitalization in Patients with Heart Failure. Int J Cardiovasc Sci 2017;30:81-90.

Submission: October, 8, 2019

Acceptance: November 8, 2019 